\title{
Salud Pública Revolucionaria Cubana
}

Hoy podemos hablar, como indica el título de este texto, de salud pública revolucionaria. Así es nuestro sistema de salud y así son nuestros servicios de salud porque se fundamenta en la ideología y política de la revolución y porque esta salud pública se ha desarrollado durante 50 años atendiendo al sentido de cada momento histórico y ha cambiado en cada momento lo que debe ser cambiado. Otro principio de su desarrollo ha sido la ética que preside todo el trabajo sanitario y asistencial, que impregna al personal que formamos para el sistema.

Son muchos los resultados relevantes de la salud pública revolucionaria cubana, que debieron partir de la eliminación de la corrupción en el aparato estatal del organismo rector del sector de la salud en el régimen pasado, hasta organizar el sistema actual, único, estatal, al alcance de todas y todos sin limitaciones de ningún tipo, científicamente sustentado, abierto a la participación popular y solidario nacional e internacionalmente.

En un recuento de por qué y cómo se construyó el sistema actual, es obligado recordar su origen en la atención que los guerrilleros del Ejército Rebelde brindaron a la población campesina y a pequeños poblados durante la guerra contra la tiranía. La ética de la práctica asistencial, que aplicó a civiles recursos que se cuidaban para los combatientes, de un ejército que en su avance decidió no dejar sin servicios a la población de zonas liberadas donde ya habían prestado asistencia, y que en primera oportunidad organizó un servicio para la población, excluida hasta entonces, que nunca había contado con servicio alguno.

Salud Pública Revolucionaria que tuvo vocación e hizo de su práctica la integración de la prevención y la atención primero, y de la docencia y la investigación después. Que con el arma de las vacunas erradicó una enfermedad a sólo tres años del triunfo armado del movimiento revolucionario. Que hoy es paradigma en la protección de la salud de la niñez, en la atención a las víctimas de desastres, en prestar servicios de alto costo de modo gratuito a los más modestos individuos, lo mismo en el país que fuera de él. Un sistema donde no se hace comercio con la salud de las personas.

Un país en absoluta dependencia tecnológica en materia de salud, como era dependiente también su economía, se ha levantado hasta dominar campos del conocimiento y tecnológicos al más avanzado nivel de desarrollo mundial, ejemplo de ello son la producción de vacunas profilácticas y terapéuticas, algunas únicas en el mundo; el dominio de técnicas quirúrgicas modernas como las de mínimo acceso, la cirugía esterotáxica, la cirugía ortognática y la trasplantología; el desarrollo de la 
ingeniería genética y la biotecnología. También avanzando en el campo de la epidemiología, las ciencias sociales aplicadas a la salud y en la educación médica.

Todo esto es resultado del trabajo abnegado de millones de cubanos y cubanas bajo condiciones difíciles por realizarse a la par que se libra una guerra ideológica, económica, bajo ataques terroristas y con agresión mediática sostenidas por cincuenta años, en que el pueblo que elevó su educación y optó por el socialismo, gana día a día nuevas batallas por su soberanía y su desarrollo.

No es un milagro, es obra del guía de la revolución, el Comandante en Jefe Fidel Castro Ruz.

Francisco Rojas Ochoa 